\title{
The expression of fibroblast growth factor receptors during early bovine conceptus development and pharmacological analysis of their actions on trophoblast growth in vitro
}

\author{
Manabu Ozawa ${ }^{1,+}$, Qi-En Yang ${ }^{1, \neq}$ and Alan D Ealy ${ }^{1,2}$ \\ ${ }^{1}$ Department of Animal Sciences, University of Florida, Gainesville, Florida 32611, USA and ${ }^{2}$ Department of Animal \\ and Poultry Sciences, Virginia Polytechnic Institute and State University, 3430 Litton-Reaves Hall, Blacksburg, Virginia \\ 24061, USA \\ Correspondence should be addressed to A D Ealy at Department of Animal and Poultry Sciences, Virginia Polytechnic Institute and \\ State University; Email: ealy@vt.edu \\ ${ }^{\dagger} \mathrm{M}$ Ozawa is now at Institute of Medical Science, University of Tokyo, Tokyo 108-8639, Japan \\ ${ }^{\ddagger}$ Q-E Yang is now at School of Molecular Biosciences, Washington State University, Pullman, Washington 99164-7520, USA
}

\begin{abstract}
The overall aim of this work was to examine the expression profiles for fibroblast growth factor receptors (FGFRs) and describe their biological importance during bovine pre- and peri-implantation conceptus development. FGFR1 and FGFR2 mRNAs were detected at 1-, 2-, 8-cell, morula and blastocyst stages whereas FGFR3 and FGFR4 mRNAs were detected after the 8-cell stage but not earlier.

The abundance of FGFR1, FGFR3, and FGFR4 mRNAs increased at the morula and blastocyst stages. Immunofluorescence microscopy detected FGFR2 and FGFR4 exclusively in trophoblast cells whereas FGFR1 and FGFR3 were detected in both trophoblast cells and inner cell mass in blastocysts. Neither transcripts for FGF10 nor its receptor (FGFR2b) were temporally related to interferon $\tau$ (IFNT) transcript profile during peri- and postimplantation bovine conceptus development. A series of studies used a chemical inhibitor of FGFR kinase function (PD173074) to examine FGFR activation requirements during bovine embryo development. Exposing embryos to the inhibitor $(1 \mu \mathrm{M})$ beginning on day 5 post-fertilization did not alter the percentage of embryos that developed into blastocysts or blastocyst cell numbers. The inhibitor did not alter the abundance of $C D X 2$ mRNA but decreased $(P<0.05)$ the relative abundance of IFNT mRNA in blastocysts. Exposing blastocysts to the inhibitor from days 8 to 11 post-fertilization reduced $(P<0.05)$ the percentage of blastocysts that formed outgrowths after transfer to Matrigel-coated plates. In conclusion, each FGFR was detected in bovine embryos, and FGFR activation is needed to maximize IFNT expression and permit outgrowth formation.
\end{abstract}

Reproduction (2013) 145 191-201

\section{Introduction}

Fibroblast growth factors (FGFs) encompass a large class of autocrine, paracrine, endocrine, and intracrine factors. More than 20 genes encode FGFs in mammals, including bovids (Elsik et al. 2009, Zimin et al. 2009, Oulion et al. 2012). The FGFs interact with a group of tyrosine kinase receptors encoded by four genes in mammals (termed FGFR1/2/3/4). Alterative splicing events observed in several species generate an array of receptor isotypes with disparate ligand binding and signaling capabilities (Powers et al. 2000, Bottcher \& Niehrs 2005). One predominant splicing event occurs within the third IgG-like extracellular domain in three of these receptors (FGFR $1 / 2 / 3)$, and the excision of one or two exons generates receptor subtypes that recognize different FGFs in various mammals, including ruminants
(Johnson et al. 1991, Chen et al. 2000, Elsik et al. 2009, Zimin et al. 2009).

Several actions for FGFs have been described during embryogenesis. FGFs are required for the emergence and proliferation of extraembryonic endoderm in mice, cattle, and humans (Kuijk et al. 2008, Cockburn \& Rossant 2010, Yamanaka et al. 2010, Yang et al. 2011a). Maintenance of trophoblast lineage is also controlled by FGFs. One of the first described activities in this regard was the necessity for FGF4 to maintain trophoblast stem cells in an undifferentiated state in mice (Feldman et al. 1995, Tanaka et al. 1998). Not all mammals show this need for FGF4 or another FGF to stimulate trophoblast stem cell proliferation and block differentiation. Trophoblast cells from the rhesus monkey and common vole (Microtus rossiaeneridionalis) proliferate without differentiation in the absence of exogenous factors, including 
A

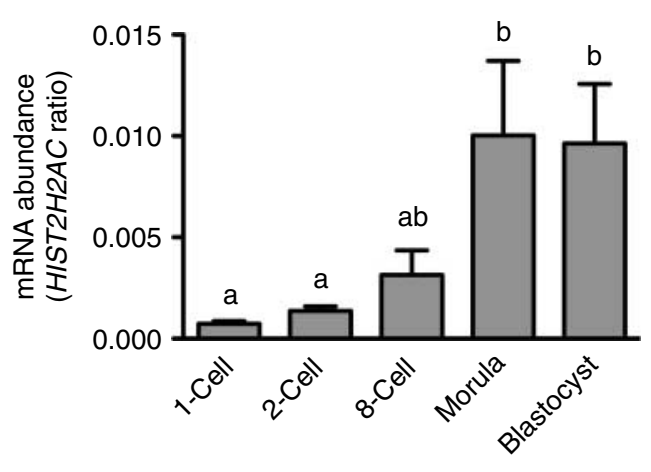

B

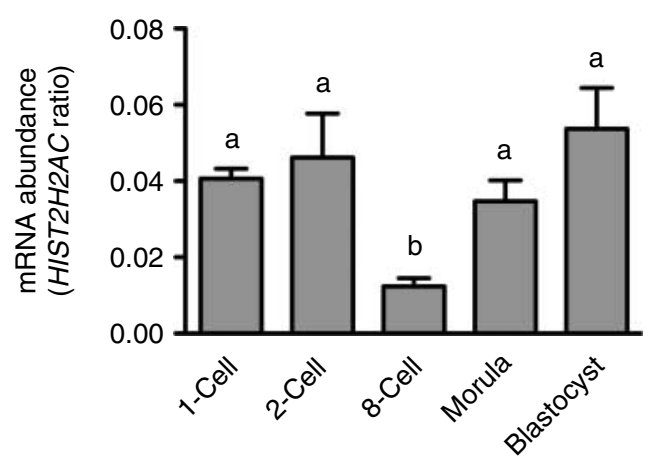

C

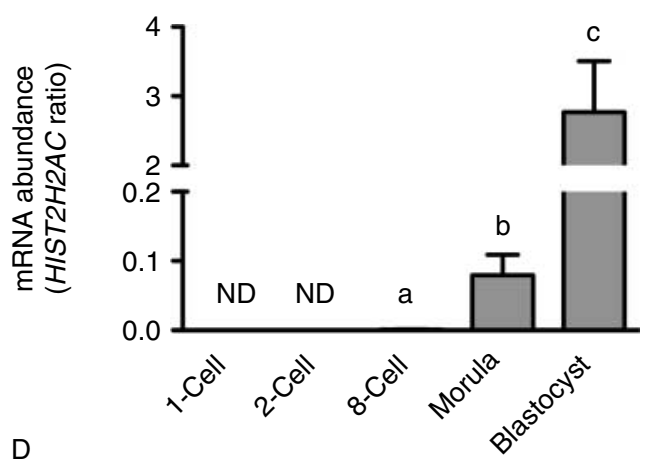

FGFR4

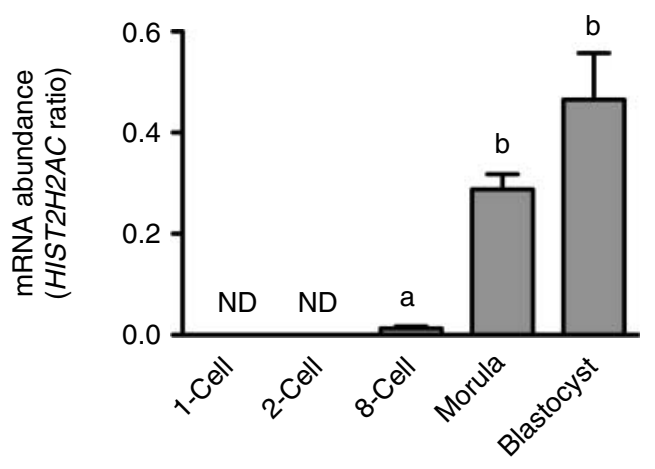

FGFs (Vandevoort et al. 2007, Grigor'eva et al. 2009). Likewise, trophoblast cells derived from ungulates (cattle, sheep, and pigs) proliferate in the absence of FGFs (Talbot et al. 2000, Shimada et al. 2001, La Bonnardiere et al. 2002, Dunlap et al. 2006, Michael et al. 2006).

Although exogenous FGFs are not required for trophoblast cell proliferation and survival, FGF activities exist in trophoblast cells. Several FGFs stimulate interferon $\tau$ (IFNT) production. Trophoblast cell-derived IFNT is the maternal recognition of pregnancy hormone in ruminants (Ealy \& Yang 2009). Several FGFs (e.g. FGF1, FGF2, FGF7, and FGF10) stimulate IFNT mRNA and protein production in bovine trophoblast cell lines and blastocysts through a PKC- $\delta$-dependent mechanism (Michael et al. 2006, Cooke et al. 2009). FGF2 and FGF10 also stimulate migration of bovine and ovine trophoblast cells (Yang et al. 2011b). Collectively, these observations indicate that FGF signals influence trophoblast cell behavior as these cells rapidly proliferate, prepare for adhesion to the uterine lining, and produce IFNT.

The need for FGF signals during the initial stages of bovine embryo development is not clear. An FGF that has been examined recently is FGF2, or basic FGF. Transcripts for FGF2 and several of the FGFR subtypes that react with FGF2 have been identified in bovine embryos during early development (Daniels et al. 2000, Cooke et al. 2009). The uterine endometrium also produces FGF2 throughout the estrous cycle and early pregnancy in sheep and cattle, and immunoreactive FGF2 is detected in uterine flushes during diestrus (Michael et al. 2006, Ocon-Grove et al. 2008). In some studies, providing FGF2 during bovine embryo culture improved subsequent blastocyst formation (Larson et al. 1992, Neira et al. 2010). However, previous studies from this laboratory failed to detect positive effects of FGF2 on blastocyst formation unless large amounts of recombinant protein were provided (500-1000 ng/ml; Fields et al. 2011). The overall aim of this work was to resolve whether embryo-derived FGFs and FGFR signaling is essential during early embryo development in cattle. Specific objectives were to describe the expression of FGFRs during early and pre-/peri-implantation conceptus development in cattle and define early developmental events that require FGFR activity.

Figure 1 The relative abundance of FGFR1/2/3/4 mRNAs throughout early bovine conceptus development. Total cellular RNA was extracted from IVP bovine embryos collected either $24 \mathrm{~h}$ after fertilization (1-cell; presumptive zygotes) or at the 2-cell, 8-cell, morula or blastocyst stages ( $n=5$ replicate studies, ten embryos/time point/replicate). Quantitative RT-PCR was completed to determine the relative abundance of FGFR1/2/3/4 (A, B, C and D respectively). Data are presented relative to the abundance of the reference transcript $(H I S T 2 H 2 A C)$. Different superscripts depict differences in mRNA abundance within each panel $(P<0.05)$. 


\section{Results}

\section{Expression profiles for FGFR1/2/3/4 during pre-implantation conceptus development}

The ontogeny of FGFR expression at the initial stages of bovine embryo development has not been examined previously. Therefore, a study was completed to describe the expression profiles for each FGFR throughout early embryogenesis (Fig. 1). Abundance of HIST2H2AC mRNA was consistent from the 1-cell to blastocyst stage and was used as the endogenous control. Transcripts for FGFR1 were detected throughout early development, but the relative abundance of FGFR1 mRNA was greater $(P<0.05)$ in morulae and blastocysts than 1 - and 2-cell embryos (Fig. 1A). Similar levels of FGFR2 mRNA were detected throughout early development with the exception of 8-cell embryos, which contained less $(P<0.05)$ mRNA than other stages (Fig. 1B). Transcripts for FGFR3 and FGFR4 were not detected in 1- and 2-cell embryos but were detected in 8-cell embryos (Fig. 1C and D). The relative abundance of FGFR3 and FGFR4 mRNA increased $(P<0.05)$ in morulae and blastocysts.

\section{Immunolocalization of FGFRs in bovine blastocysts}

Immunofluorescence was used to examine the localization of each FGFR protein from in vitro-produced (IVP) embryos. Immunoreactive FGFR1, FGFR2,
FGFR3, and FGFR4 could not be detected in 1-, 2-, or 8-cell embryos (data not shown), but immunoreactivity for each receptor was detected at the blastocyst stage (Fig. 2). Morulae were not examined. FGFR1 and FGFR3 proteins were detected in both the inner cell mass and the trophoblast cells whereas FGFR2 and FGFR4 localized to the trophoblast cells.

\section{Expression profiles of selected transcripts during peri- and postimplantation periods}

The association between FGF10 and IFNT was of interest because both are produced by the peri-implantation conceptus around the time when IFNT production is maximal, suggesting that FGF10 may assist in the control of peak IFNT production (Cooke et al. 2009). Also, the FGF10 receptor, termed FGFR2b (or keratinocyte growth factor receptor, a spliced variant of the FGFR2 subfamily), is produced by trophectoderm (TE) during the peri-implantation period in sheep (Chen et al. 2000), but its expression throughout early embryo development remained unexplored.

A biphasic pattern of IFNT mRNA abundance was detected throughout pre-, peri-, and post-attachment periods of bovine conceptus development (Fig. 3A). IFNT mRNA was detected in blastocysts, and mRNA abundance increased $(P<0.05)$ in ovoid conceptuses collected at day 14 of pregnancy. The relative abundance
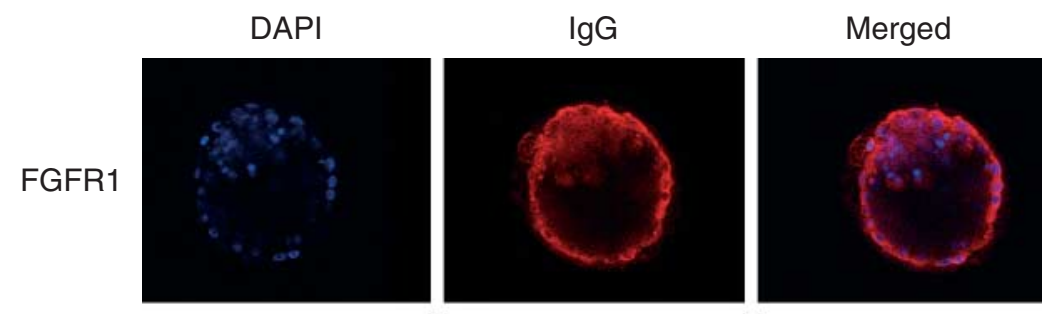

FGFR2
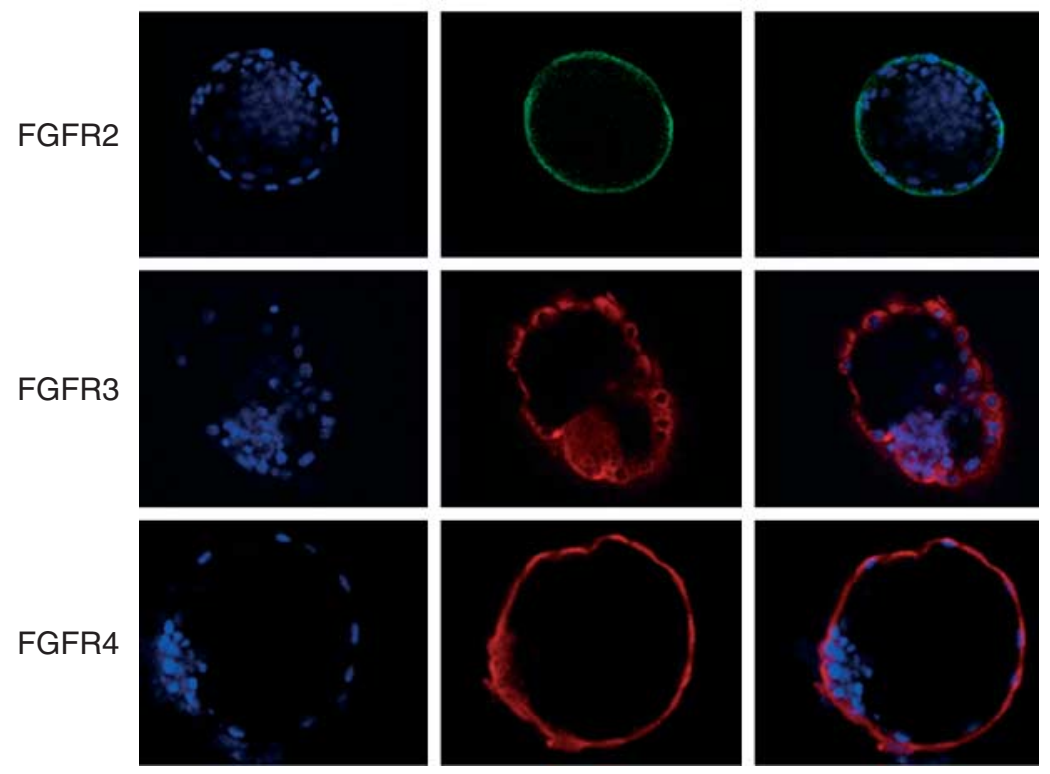

Figure 2 Localization of immunoreactive FGFR1/2/3/4 protein within bovine blastocysts. Representative photomicrographs of blastocysts exposed to antibodies for FGFR1, FGFR2, FGFR3, or FGFR4. The left column contains nuclear DAPI staining for each blastocyst, the center column contains the antibody-specific immunofluorescence, and the right column contains the overlay of DAPI and immunoreactive stains $(100 \times$ magnification). 
A

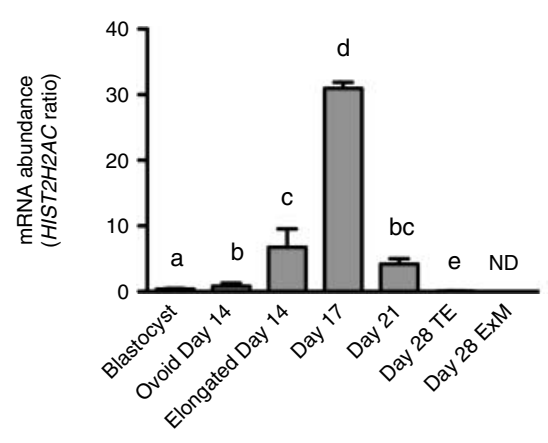

C

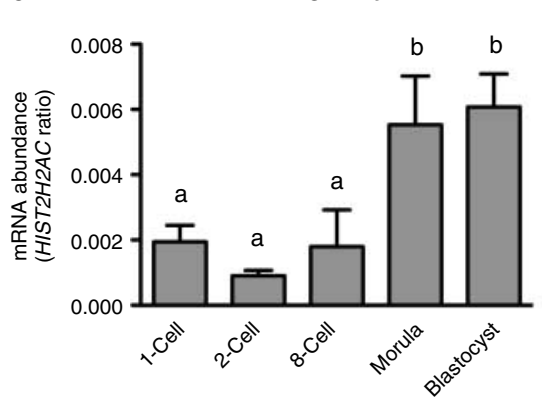

B

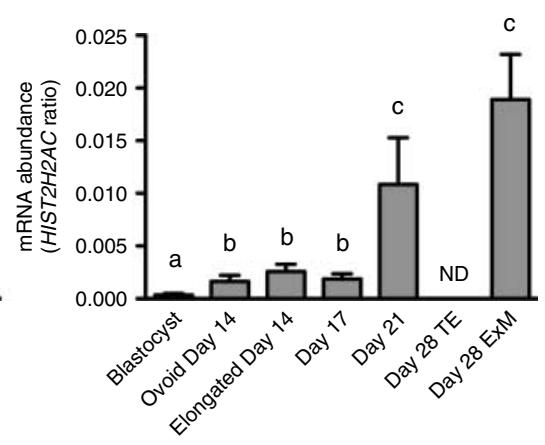

D

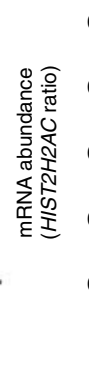

FGFR2b

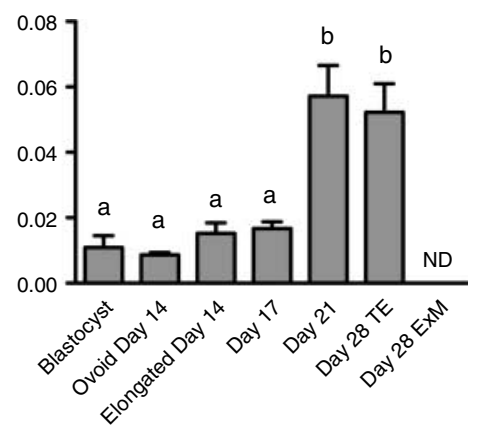

Figure 3 Transcript profiles for IFNT, FGF10, and the cognate FGF10 receptor (FGFR2b) throughout early conceptus development. Total cellular RNA was extracted from IVP bovine embryos collected either $24 \mathrm{~h}$ after fertilization (1-cell; presumptive zygotes) or at the 2-cell, 8-cell, morula or blastocyst (day 8 post-IVF) stages $(n=5-6$ replicate studies, ten embryos/time point/replicate). At day 8 post-IVF $(n=6$ blastocyst pools), from conceptuses collected from superovulated cows at day 14 (ovoid or elongating; $n=6$ conceptus pools) and day 17 ( $n=6$ conceptus pools) post-insemination, and from conceptuses collected from non-superovulated cows at day 21 ( $n=5$ samples) and day $28(n=3$ samples) post-insemination. At day 28 , trophectoderm (TE) and extraembryonic mesoderm were separated before snap-freezing and were processed as separate samples. (A) IFNT mRNA abundance between days 8 and 28; (B) FGF10 mRNA abundance between days 8 and 28; (C) FGFR2b mRNA abundance between days 1 and 8 ; and (D) FGFR $2 b$ mRNA abundance between days 8 and 28 . Transcripts of interest are presented relative to the abundance of a reference transcript (HIST2H2AC for early embryo; GAPDH for days 8-28 conceptuses). Different superscripts depict differences in mRNA abundance within each panel $(P<0.05)$. of IFNT mRNA increased $(P<0.05)$ further in elongating conceptuses collected at day 14. Maximal amounts of IFNT mRNA were detected in elongated conceptuses collected at day 17. IFNT mRNA was detected at day 21 and in TE at day 28, albeit at very low levels. No IFNT mRNA was detected in extraembryonic mesoderm (ExM) at day 28.

Both FGF10 and FGFR2b mRNAs were detected throughout all the stages of conceptus development. However, neither expression pattern mirrored that of IFNT. The transcript abundance for FGF10 was low in blastocysts and increased $(P<0.05)$ in conceptuses collected at day 14 (Fig. 3B). The relative abundance of FGF10 mRNA was unchanged in ovoid and elongating conceptuses collected at day 14 and conceptuses collected at day 17 and was increased $(P<0.05)$ at days 21 and 28. FGF10 mRNA was only detected in ExM at day 28. Two studies examined the expression profiles for FGFR2 $b$. The first study examined FGFR2 $b$ mRNA abundance during the initial stages of bovine embryonic development (Fig. 3C). FGFR2b mRNA was detected in 1-, 2-, and 8-cell embryos, and its relative abundance increased $(P<0.05)$ at morula and blastocyst stages. RNA collected at subsequent stages of bovine conceptus development (Fig. 3D) determined that the relative abundance of FGFR2 $b$ mRNA remained unchanged between the blastocyst stage and day 17. An increase $(P<0.05)$ in FGFR2b mRNA abundance was detected at day 21 and in TE at day 28. No FGFR2b mRNA was detected in ExM.

\section{FGFR signaling requirements for embryo development and IFNT expression}

The requirement of FGFR signaling during pre-implantation embryo development was examined by blocking FGFR activation with PD173074, a cell-permeable FGFR kinase inhibitor used by this laboratory and others to examine FGFR-mediated events in bovine tissues (Yang et al. 2011a, Kuijk et al. 2012, Zhang \& Ealy 2012). This compound competitively inhibits ATP binding to receptor kinase regions of FGFRs (Mohammadi et al. 1998, Skaper et al. 2000). Studies have not been completed to verify the specificity of this compound to bovine FGFRs, but this specificity is probable given the high degree of sequence conservation in FGFR tyrosine kinase regions of cattle and humans ( $>98 \%$ amino acid sequence identity with corresponding human FGFR kinase domains). A pilot study verified that PD173074 inhibited FGF2-dependent responses in a bovine trophoblast cell line (CT1). Cells were exposed to $10 \mathrm{ng} / \mathrm{ml}$ FGF2 and various concentrations of PD173074. In nonPD173074-treated controls, FGF2 increased $(P<0.05)$ IFNT mRNA abundance by $5.0 \pm 1.6$-fold. No significant changes in FGF2-induced IFNT mRNA abundance were detected by providing 10 or 100 nM PD173074, but exposing cells to $1 \mu \mathrm{M}$ PD173074 for $24 \mathrm{~h}$ before FGF2 treatment prevented the FGF2 effect $(0.81 \pm 0.15$-fold effect vs control).

Exposing embryos to $1 \mu \mathrm{M}$ PD173074 from days 5 to 8 post-IVF did not affect blastocyst development rate and 

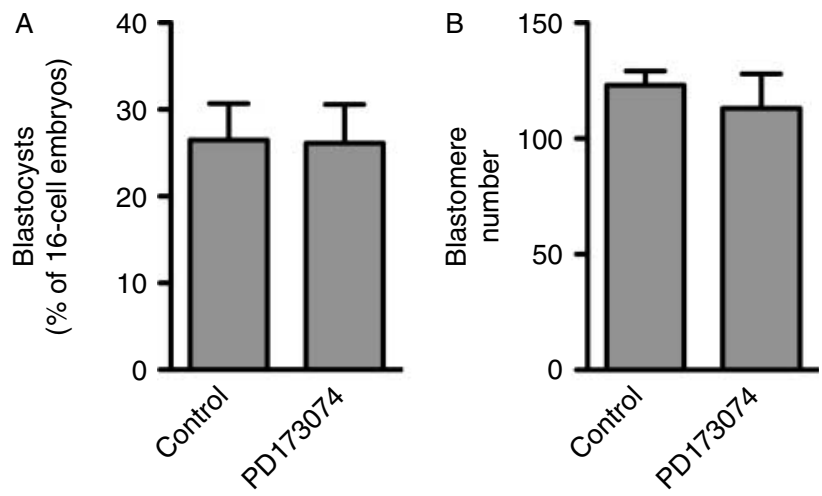

CDX2
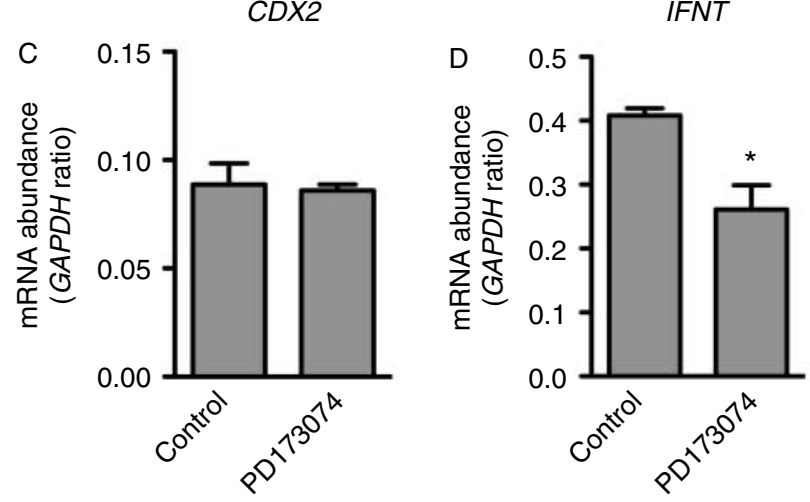

Figure 4 Inhibition of FGFR activity with PD173074 does not affect embryo development or trophoblast gene expression during in vitro culture. Bovine embryos were generated by IVP. Embryos containing $\geq 8$ blastomeres were collected at day 5 post-IVF and incubated in medium containing $1 \mu \mathrm{M}$ PD173074 or carrier only (control). In one study, rates of blastocyst formation were determined at day $8(A)$ and blastocysts were fixed and stained to determine blastomere numbers (B) ( $n=6$ replicate studies, $28-31$ embryos/treatment/replicate). In another study, blastocysts ( $n=4$ replicate studies, $10-15$ blastocysts/treatment/ replicate) were collected and RNA was extracted at day 8 and qRT-PCR was used to determine the abundance of CDX2 (C) and IFNT (D) transcripts relative to the abundance of the reference transcript $(G A P D H)$. The asterisk depicts differences between PD173074-treated and control samples $(P<0.05)$.

total cell numbers in blastocysts (Fig. $4 \mathrm{~A}$ and B). Also, no changes in mRNA abundance of $C D X 2$, a trophoblast lineage marker, were observed (Fig. 4C). However, PD173074 treatment decreased $(P<0.05)$ IFNT mRNA abundance (Fig. 4D).

\section{Interruption in blastocyst outgrowth development following FGFR inhibition}

The need for FGFR signals after blastocyst formation was examined by assessing the ability of blastocysts to adhere to Matrigel-coated plates and form trophoblast outgrowths (Fig. 5). Individual blastocysts were incubated in growth medium containing $1 \mu \mathrm{M}$ PD173074 or carrier only from days 8 to 11 post-IVF, then medium was exchanged, and blastocysts were cultured without treatments thereafter. In controls, trophoblast outgrowths were evident in a low proportion of blastocysts $(<3 \%)$ as early as day 10 . Additional outgrowths were detected thereafter until day 15 (Fig. 5A). No additional outgrowths were formed after day 15. Exposure to PD173074 delayed $(P<0.05)$ the time when outgrowth development was first observed (day 12). The treatment also decreased $(P<0.05)$ the percentage of blastocysts that formed outgrowths at each day of examination (Fig. 5A). A large variation in outgrowth size (i.e. surface area) was evident in both treatments (Fig. 5B). A numerical reduction in outgrowth size was observed between controls and PD173074-treated blastocysts, but this outcome was not statistically significant $(P=0.15)$.

\section{Discussion}

The first major focus of this work was to identify stages when bovine embryos are potentially responsive to FGFs by describing the ontogeny of FGFR mRNA and protein production during bovine embryogenesis. Differences in
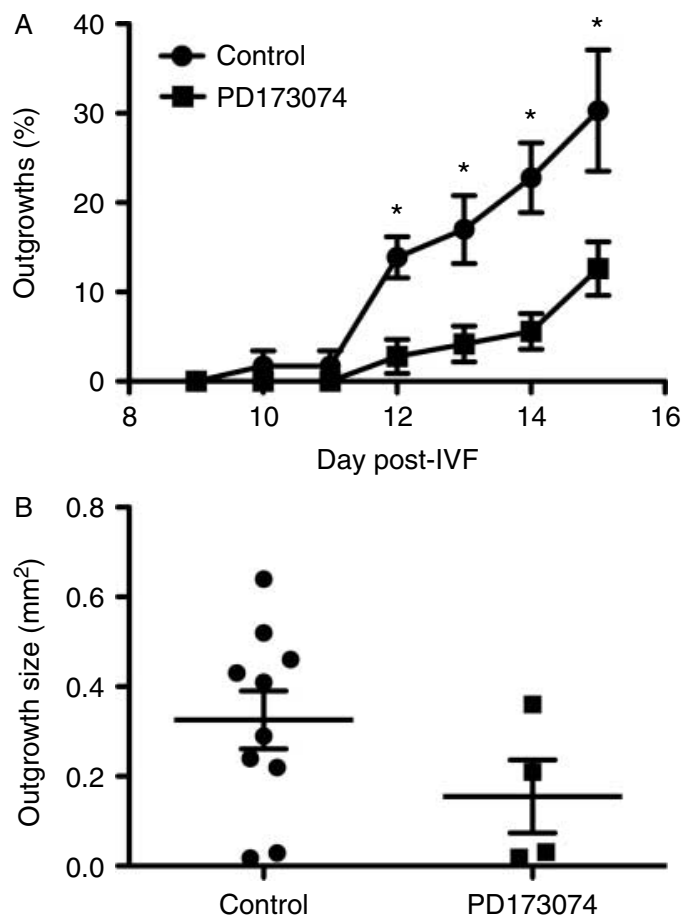

Figure 5 Exposing blastocysts to PD173074 compromises subsequent outgrowth formation. Bovine embryos were generated by IVP. Blastocysts were collected at day 8 post-IVF and incubated in individual wells of a 24-well plate containing Matrigel basement membrane matrix with medium containing $1 \mu \mathrm{M}$ PD173074 or carrier only (control; $n=6$ replicate studies, 10-14 blastocysts/treatment/ replicate). At day 11 post-IVF, medium was exchanged with medium lacking PD173074. The incidence of blastocyst outgrowth formation was examined daily until day 15 (A). Size of outgrowths was determined at day 15 (B). Asterisk $\left(^{*}\right)$ indicates differences in outgrowth formation due to treatment within day $(P<0.05)$. 
expression profiles exist between FGFR subtypes. Of particular note is the presence of FGFR1 and FGFR2 transcripts throughout early embryonic development vs the presence of FGFR3 and FGFR 4 transcripts only after embryonic genome activation (8- to 16-cell stage in bovine embryos; Telford et al. 1990). Transcripts found in embryos before embryonic genome activation are synthesized by the maternal genome before ovulation and stored in the cytoplasm during fertilization and the first several days of embryogenesis (Gilchrist et al. 2008). Therefore, both maternal and embryonic FGFR 1 and FGFR2 transcripts exist in the bovine embryo whereas only embryonic transcripts were detected for FGFR3 and FGFR4. The loss of FGFR2 mRNA at the 8 -cell stage likely reflects the use and degradation of maternal transcripts before embryonic transcription begins. Transcripts for FGFR1, FGFR3, and FGFR4 exhibited marked increases in their relative abundance at the blastocyst stage in cattle when compared with their abundance at the 8-cell stage. The pattern of FGFR2 expression was different in this regard, and no dramatic changes in overall transcript abundance occurred after embryonic genome activation.

It is unclear what roles FGFR1 and FGFR2 may be playing in early bovine embryo development. The major spliced variants for these receptors react with numerous FGFs, including FGF2 and FGF10 (Powers et al. 2000, Bottcher \& Niehrs 2005), and their presence likely contributes to the embryotrophic activities for FGF2 during early bovine embryogenesis (Larson et al. 1992, Neira et al. 2010). Interestingly, the necessity for FGFR1 and FGFR2 activity is not evident until after blastocyst formation in mice. Early embryogenesis occurs normally in knock-out models of each receptor, and loss of FGFR1 function induces a postimplantation embryonic lethal phenotype characterized by defects in mesoderm and endoderm migration and cell fate determination (Deng et al. 1994, 1997, Yamaguchi et al. 1994) whereas loss of FGFR2 function generates a post-blastocyst stage embryonic lethality characterized by lack of visceral endoderm and reduced TE mass (Arman et al. 1998). Epiblast-derived FGF4 interacting with the FGFR2Cspliced variant is responsible for these activities. Variants of FGFR2 also appear important for conceptus development in ruminants. FGF2, which reacts with FGFR2C and several other FGFRs, is produced by the endometrial epithelium and peak secretion occurs around the time of conceptus elongation in sheep (Michael et al. 2006, Ocon-Grove et al. 2008). Also, the other major FGFR2spliced variant, FGFR2b, is expressed in bovine, ovine, and porcine TE before implantation and its primary ligands (FGF7 and FGF10) are produced in endometrium before and during implantation (Chen et al. 2000, Ka et al. 2001, Cooke et al. 2009, Yang et al. 2011a). In the sheep uterus, FGF10 production from the uterine stroma is controlled by progesterone and its interaction with FGFR2b in the luminal epithelium is associated with uterine events that control early conceptus development (Chen et al. 2000, Satterfield et al. 2008). Also, immature binucleate cells contain FGFR2 transcripts, and perhaps endometrial FGF10 regulates trophoblast differentiation, migration, and hormone production (Pfarrer et al. 2006).

Not only did FGFR3 and FGFR4 mRNA profiles differ from the other FGFRs but the relative transcript abundance of these FGFRs was much greater than the other receptors. At the blastocyst stage, FGFR3 mRNA abundance was 15- to 300-fold greater than FGFR2 and FGFR 1 respectively. Similarly, FGFR 4 mRNA was 10 - to 40 -fold greater in abundance than FGFR2 and FGFR1 respectively. Neither absolute mRNA concentrations nor adjustments to the relative abundance measurements were made here; therefore, direct comparisons between these transcripts cannot be completed. However, the high expression of these transcripts suggests that these receptors may be important during early embryogenesis. It is unclear what these functions may be. FGFR3 reacts with several FGFs (FGF1 and FGF9 for FGFR3b; FGF1, FGF2, FGF4, FGF8, and FGF9 for FGFR3b; Itoh \& Ornitz 2004), and it is expressed through gestation in human and rodent placentae and localizes to extraembryonic endoderm and trophoblast giant cells in mice (Rappolee et al. 1998, Anteby et al. 2005). Mutations in FGFR3 function in mice and humans are associated with skeletal dysplasia, notably achondroplasia during fetal development and urothelial tumorigenesis in adulthood (lyer \& Milowsky 2012, Laederich \& Horton 2012). No spliced variants exist for FGFR4. Numerous FGFs interact with FGFR4 (e.g. FGF1, FGF2, FGF4, FGF6, FGF8, and FGF9; Itoh \& Ornitz 2004), and it is expressed throughout gestation in the mouse and human placenta (Rappolee et al. 1998, Anteby et al. 2005). In the human placenta, FGFR4 mRNA localizes to several trophoblast cell types at the decidualtrophoblast border, suggesting a role in maintaining this interface (Anteby et al. 2005). FGFR4 is also needed during neural development and is linked with various cancers in several species (Marchal et al. 2009, Ota et al. 2010, Tenhagen et al. 2012).

Detecting FGFR proteins at the blastocyst stage is consistent with the transcript profiles for FGFR3 and FGFR4 but it is not clear why immunoreactive FGFR1 and FGFR2 were not detected at earlier stages of development. Perhaps posttranscriptional events (e.g. RNA silencing) limit FGFR protein translation during early stages of embryo development. Alternatively, perhaps the sensitivity of detection was insufficient to visualize immunoreactivity at these early stages. Nonetheless, the detection of each FGFR transcript and protein at the blastocyst stage suggests that each major FGFR subtype is available to interact with FGFs at this stage. FGFR2 exhibits a trophoblast-specific localization pattern in mice, pigs, and sheep (Haffner-Krausz et al. 1999, Chen et al. 2000, Ka et al. 2007). This work demonstrated the same expression profile in cattle. 
The localization patterns of other FGFRs have not been characterized previously at blastocyst stage. These outcomes indicate that FGFR4 localizes solely to the trophoblast cell in blastocysts whereas trophoblast and inner cell mass cells express FGFR1 and FGFR3.

The expression profile for FGFR2b and one of its ligands, FGF10, was examined throughout the pre-, peri-, and postimplantation stages in cattle to examine a potential linkage between this FGF ligand/receptor system and peak IFNT expression in peri-attachment conceptuses. Recent work from this laboratory detected an increase in the relative abundance of embryonic FGF10 mRNA around the time of bovine conceptus elongation (Cooke et al. 2009), thereby implicating FGF10 as a potential mediator of the rapid surge in IFNT production during elongation. However, work presented herein found no correlations in expression patterns. The IFNT mRNA profile was identical to that reported by others (Kubisch et al. 1998, Ealy et al. 2001, Robinson et al. 2006). A pronounced increase in IFNT mRNA occurred with elongation, and maximal transcript abundance was evident at day 17 whereas the FGF10 mRNA profile remained unchanged around the time of conceptus elongation (days 14-17). Also, FGFR2b mRNA abundance remained unchanged during conceptus elongation. Although FGF10 and FGF2b do not appear to be principle players defining the pattern on IFNT expression, this and other FGFs certainly appear to play a role in regulating the constitutive production of IFNT in ruminant TE (Michael et al. 2006, Cooke et al. 2009). Also, work presented herein found that blocking FGFR kinase activity reduces IFNT mRNA abundance. No changes in CDX2 mRNA, a trophoblast lineage marker, were noted, indicating that the number and overall transcriptional activity of trophoblast cells is not altered with this inhibitor. Rather, this outcome supports the hypothesis that blastocyst-derived FGFs (e.g. FGF2 and FGF10) mediate constitutive IFNT production in cattle. With that said, to date, no studies have directly examined the necessity for FGFR signals during peak IFNT expression in ruminants. Work at this critical stage of pregnancy is needed before we can claim whether FGF signaling is required for maximal IFNT production or if these signals are only being used before the peak in IFNT production at days 14-17 in cattle.

The second major focus of this work was to describe functions for FGFRs during early embryonic development. The necessity for specific FGFRs has not been described in the cow, but as described previously, lossof-function mutation studies on mice determined that FGFR1 and FGFR2 are vital for post-blastocyst survival and FGFR3 and FGFR4 are important after implantation (Deng et al. 1994, Yamaguchi et al. 1994, Arman et al. 1998, lyer \& Milowsky 2012, Laederich \& Horton 2012). Present work failed to detect any adverse developmental effects by inhibiting FGFR activity before blastocyst formation. A previous study using another FGFR kinase domain inhibitor (SU5402) observed that fewer cultured embryos formed blastocysts at day 7 but not at day 8 post-fertilization (Fields et al. 2011). Blastocyst formation at day 7 was not examined in this project, but no differences in blastocyst formation, blastomere numbers, and the expression of $C D X 2$ were detected at day 8 postfertilization in embryos exposed to PD173074. Therefore, FGFR inhibition seems to impact the timing of blastocyst formation but not overall blastocyst formation, embryonic numbers, and lineage commitment to trophoblast cells. It remains possible that FGFs function, at least in part, as cooperative factors during early embryonic development in cattle. One recent study found that the positive effect of FGF2 supplementation on in vitro bovine blastocyst development was enhanced when it was co-supplemented with other factors, such as insulin-like growth factors or colony-stimulating factor 2 (Neira et al. 2010). Another study failed to detect a benefit of FGF2 supplementation on in vitro bovine embryo development unless it was co-cultured with transforming growth factor $\beta$ (Larson et al. 1992).

The last study examined potential impacts of inhibiting FGFR signals after blastocyst formation. Bovine blastocysts attach to basement membrane matrices, such as Matrigel, when cultured in medium containing serum (Talbot et al. 2007, Yang et al. 2011a). Exposing blastocysts to the FGFR inhibitor delayed the onset of outgrowth formation and reduced the overall rate of outgrowth formation. The size of the outgrowths at day 15 was not statistically different between groups. This is not surprising as so few outgrowths were established after exposure to the FGFR inhibitor. Observing such small outgrowths at day 15 could reflect that FGFR inhibition compromised trophoblast cell growth potential. Alternatively, observing smaller outgrowths at day 15 could simply reflect the delayed ontogeny of outgrowth formation. FGF2 and FGF10 stimulate bovine and ovine trophoblast cell migration across trans-well inserts (Yang et al. 2011b). Therefore, FGFR signaling may mediate the chemotactic, adhesive, migratory, and/ or proliferative activities required for changes in trophoblast cell morphology, adhesion and attachment, and conceptus elongation during peri-implantation development. However, it remains untested whether post-blastocyst stage development is compromised by FGFR signal interference in utero.

One aspect of the outgrowth work that remains unresolved involves pinpointing the precise timing for FGFR signal control of outgrowth formation. Temporary reductions in FGFR protein abundance have been noted by others following PD173074 treatment (Azuma et al. 2011, Lamont et al. 2011). If similar PD173074-induced reductions in FGFR expression also occur in bovine blastocysts, then these embryos may be unresponsive to endogenous FGF signals after removal of the inhibitor at day 11 post-IVF. FGFR mRNA profiles and FGFR activity assessments were not examined during and after 
PD173074 treatment. Therefore, it is not known whether the effects observed resulted from FGFR signal inhibition between days 8 and 11 post-IVF or if continued inhibition of FGFR activity after day 11 was responsible for the outcomes.

In summary, these observations provide new insights into the necessity for FGFR signaling during early embryo development in cattle. Transcripts for FGFR1 and FGFR2 were detected before embryonic genome activation and all four FGFR subtypes were detected after genome activation. Immunoreactive proteins for each FGFR localized to trophoblast cells at the blastocyst stage. FGFR1 and FGFR3 proteins were detected in the inner cell mass in blastocysts. Interference of FGFR signaling did not impact development to the blastocyst stage and blastomere numbers in blastocysts. However, this report identified that FGFR activity mediates IFNT expression in blastocysts and maximizes blastocyst outgrowth formation and spreading. This work implicates embryo-derived FGFs and FGFR signaling as important components for IFNT production and trophoblast cell adhesion in cattle.

\section{Materials and Methods \\ In vitro embryo production}

Oocyte maturation, fertilization, and embryo culture was completed as described previously (Loureiro et al. 2009, Zhang et al. 2010, Fields et al. 2011). In brief, ovaries were obtained from a local slaughterhouse (Central Beef Industries, Center Hill, FL, USA). Pools of COCs $(n=10-20)$ were collected and matured in $50 \mu \mathrm{l}$ drops of oocyte maturation medium (OMM; TCM199 containing Earle's salts (Invitrogen Corp.), $25 \mu \mathrm{g} / \mathrm{ml}$ porcine FSH (Folltropin-V, Bioniche Life Sciences, Belleville, ON, Canada), $2 \mu \mathrm{g} / \mathrm{ml}$ estradiol $17 \beta, 0.2 \mathrm{mM}$ sodium pyruvate, $50 \mu \mathrm{g} / \mathrm{ml}$ gentamicin sulfate, $1 \mathrm{mM}$ glutamine, and $1 \mathrm{mg} / \mathrm{ml}$ polyvinyl alcohol (SigmaAldrich)). After 21-22 h, COCs were placed in fertilization medium (TL-Fert (Caisson, Sugar City, ID, USA) containing $0.6 \%(\mathrm{w} / \mathrm{v})$ essentially fatty acid-free BSA and $1 \mathrm{mM} \mathrm{Na}$ pyruvate) and incubated with Percoll gradient-purified bovine spermatozoa for $8-10 \mathrm{~h}$ at $38.5{ }^{\circ} \mathrm{C}\left(5 \% \mathrm{CO}_{2}\right.$ in humidified air). A pool of semen from four bulls was used for all studies. After $8 \mathrm{~h}$ of fertilization, cumulus cells were removed by vortexing in $1000 \mathrm{U} / \mathrm{ml}$ hyaluronidase (Sigma-Aldrich) and putative zygotes were cultured in groups of 25-30 in 50 $\mu$ l drops of serum-free mSOF-BE (Millipore, Billerica, MA USA; Fields et al. 2011). Drops were covered with mineral oil and maintained at $38.5{ }^{\circ} \mathrm{C}$ in $5 \% \mathrm{CO}_{2}, 5 \% \mathrm{O}_{2}$, and $90 \% \mathrm{~N}_{2}$.

For transcript ontogeny studies, presumptive zygotes (1-cell) and 2-cell embryos were collected $24 \mathrm{~h}$ after fertilization (day 1), and 8-cell, morulae and blastocysts were collected at days 3, 5, and 8 post-IVF respectively. Pools of embryos ( $n=10 /$ pool) were generated at each collection time point. Embryos were processed immediately to extract total cellular RNA using the PicoPure RNA Isolation Kit (MDS Analytical Technologies, Sunnyvale, CA, USA).

\section{Bovine conceptus collections}

Day 14 conceptuses were collected from superovulated Holstein cows $(n=9)$ nonsurgically and sorted based on size (ovoid vs elongating; $n=3-5$ conceptuses/pool; six pools) as described previously (Cooke et al. 2009). Approximately half of the conceptuses collected at day 14 were ovoid and the remaining elongating conceptuses ranged in size from $\sim 0.5-3 \mathrm{~cm}$ in length. Day 17 conceptuses were collected from superovulated Holstein cows $(n=6)$ by flushing excised uteri following killing (Cooke et al. 2009). All conceptuses were elongated and ranged in size from 5 to $45 \mathrm{~cm}$. conceptuses were pooled in small groups $(n=3-5 /$ pool; six pools) and snap-frozen in liquid nitrogen.

Day 21 and 28 conceptuses were collected from excised reproductive tracts of non-superovulated Holstein cows ( $n=5$ and 3 cows respectively) after killing. Estrous was synchronized and induced by administering a GNRH analog (100 $\mu \mathrm{g}$ Cystorelin, Merial Limited, Duluth, GA, USA) and inserting an intravaginal progesterone-containing device (Eazi-Breed CIDR; Pfizer Corp.) for 7 days. Lutalyse $(25 \mathrm{mg}$, Pfizer Corp.) was administered at the time of CIDR removal and the GNRH analog was provided $56 \mathrm{~h}$ later. Cows were inseminated with Holstein semen (Genex Cooperative, Inc., Shawano, WI, USA) $16 \mathrm{~h}$ later. At day 21, the embryo proper was excised and the entire TE from each cow was collected and snap-frozen in liquid nitrogen. At day 28, the embryo was excised and the TE and ExM was separated and snap-frozen. The TRIzol Plus RNA Purification System containing PureLink spin columns (Invitrogen Corp.) were used to extract RNA from all samples.

\section{Quantitative RT-PCR}

RNA concentrations and integrity $\left(\mathrm{A}_{260} / \mathrm{A}_{280}\right.$ ratio $\left.\geq 1.8\right)$ were determined using the Nano Drop 2000 Spectrophotometer (Thermo Scientific, Wilmington, DE, USA). Quantitative RT-PCR (qRT-PCR) was completed using a 7300 Fast RealTime PCR System (Applied Biosystems) as described previously (Cooke et al. 2009, Zhang et al. 2010, Yang et al. 2011a). In brief, samples were incubated with RNase-free DNase (New England Biolabs, Ipswich, MA, USA) and reverse transcribed (High-Capacity cDNA RT Kit, Applied Biosystems) and amplified with SYBR Green PCR Master Mix reagent (Applied Biosystems) and normal PCR conditions (40-50 cycles of $95{ }^{\circ} \mathrm{C}$ for $15 \mathrm{~s}$ and $60{ }^{\circ} \mathrm{C}$ for $1 \mathrm{~min}$ ). Primer pairs (Table 1 ) were validated in previous work for adequate primer efficiency and correctness of amplicon sequence (Cooke et al. 2009, Zhang et al. 2010, Yang et al. 2011a). Amplification of a single PCR product for each sample was examined by dissociation curve analysis. Also, the exclusion of reverse transcriptase was included as a negative control for each sample. Histone HIST2H2AC (HIST2H2AC) was used as the transcript reference control for studies examining changes in transcript abundance from 1-cell to blastocyst stages and GAPDH was used as the reference control for studies from blastocysts to day 28 of gestation. The abundance of each reference control transcript was unchanged during the specified stages of development similar to that described previously by others (Robert et al. 
Table 1 Primers used for qRT-PCR.

\begin{tabular}{ll}
\hline Gene of interest & Primer sequences $\left(5^{\prime}-3^{\prime}\right)$ \\
\hline FGF10 & F: AGAGGACAGAAAACACGAAGGAAA \\
& R: GGTTATACTGCATCTGCAATCATTG \\
FGF 1 & R: GGTCACAGCCACGCTCTGC \\
& F: GACATCGTCCCGCAGCCGA \\
FGFR2 & R: CTGGCAGCTAAATCTCGATGAA \\
& F: GTGGAAAAGAACGGCAGTAAATA \\
FGF $2 b$ & R: GAACTATTATCCCCGAGTGCTTG \\
FGFR3 & F: GCAGCGGCTACAGGTGCTCA \\
& R: CAGGCCGCGTCCAGTAAGGG \\
FGFR4 & F: GCAGACGCTCCTCACCCGAC \\
& R: CGAGACTCACGAGGCCAGCG \\
HIST2H2AC (H2a) & F: GTCGTGGCAAGCAAGGAG \\
GAPDH & R: GATCTCGGCCGTTAGGTACTC \\
& F: ACCAGAAGACTGTGGATGG \\
IFNT & R: CAACAGACACGTTGGGAGTG \\
& F: GATCCTTCTGGAGCTGGYTG \\
& R: GCCCGAATGAACAGACTCYC \\
\hline
\end{tabular}

$\mathrm{F}$, forward primer (sense); $\mathrm{R}$, reverse primer (antisense); $\mathrm{Y}$, insertion of a $\mathrm{C}$ or T nucleotide. Primers were validated in previous work for amplification efficiency and correctness of amplification (Cooke et al. 2009, Zhang et al. 2010, Yang et al. 2011a).

2002, Purcell et al. 2009). Data were normalized based on the ratio of transcript abundance for the gene of interest to that of the reference control $\left(2^{-\mathrm{CT}}\right.$ gene of interest $\left./ 2^{-\mathrm{CT} \text { reference control }}\right)$.

\section{Immunofluorescence and confocal microscopy}

IVP bovine embryos were fixed with $4 \%(\mathrm{v} / \mathrm{v})$ paraformaldehyde in PBS for $15 \mathrm{~min}$, permeabilized for $15 \mathrm{~min}$ with $0.25 \%$ Triton X-100 in PBS, and blocked with PBS containing $5 \%(\mathrm{w} / \mathrm{v})$ BSA. Embryos were incubated overnight at $4{ }^{\circ} \mathrm{C}$ with primary antibody (FGFR1, FGFR3, and FGFR purchased from Abcam (Cambridge, MA, USA), FGFR2 (1:200, Abnova, Taipei City, Taiwan), FGFR3 (1:200, Abcam), and FGFR4 (1:100, ab65974, Abcam)). Each preparation was diluted in Trisbuffered saline containing $0.1 \%(\mathrm{v} / \mathrm{v})$ Tween 20 (TBST) and $1 \%$ $(\mathrm{w} / \mathrm{v})$ BSA. After washing, embryos were incubated in secondary antibody (anti-mouse IgG conjugating FITC (1:1000, Abcam) or anti-rabbit IgG conjugating Alexa Fluor 555 (1:1000, Cell Signaling Technology, Danvers, MA, USA)) prepared in TBST-BSA for $1 \mathrm{~h}$ at room temperature. Nuclei were labeled with 4',6-diamidino-2-phenylindole (DAPI) $(1 \mu \mathrm{g} / \mathrm{ml})$. Fluorescence signals were visualized with a Zeiss Pascal LSM5 Confocal Laser Scanning Microscope (Zeiss, Göttingen, Germany). Western blotting was completed with bovine cell lysates (CT1 cells and Madin-Darby bovine kidney (MDBK) cells) to verify that antibodies recognized a single protein band of the approximate molecular weight specified for each FGFR (data not shown).

\section{FGFR inhibition during early embryo development}

In one study, $\geq 16$-cell embryos were collected at day 5 post-IVF and transferred to $\mathrm{mSOF}$ medium containing PD173074 (1 $\mu \mathrm{M}$, Stemgent, Cambridge, MA, USA) or vehicle only $(0.005 \%$ DMSO) ( $n=6$ replicate studies, $28-31$ embryos/ treatment/replicate). At day 8 , embryos were examined for their progression to the blastocyst stage, and blastocysts were stained with DAPI to determine blastomere numbers as described earlier.

In another study, pools of blastocysts derived from cultures containing or lacking PD173074 were collected and RNA was extracted as described previously ( $n=4$ replicate studies; 10-15 blastocysts/treatment/replicate). Effects of PD173074 treatment on NANOG, GATA4, CDX2, and IFNT mRNA abundance were examined by qRT-PCR as described previously (Zhang et al. 2010, Yang et al. 2011a).

\section{FGFR inhibition and outgrowth formation}

Blastocyst outgrowth cultures were completed as described previously (Yang et al. 2011a). Blastocysts were collected at day 8 post-IVF and individual blastocysts were placed into Matrigel-coated wells $\left(0.95 \mathrm{~cm}^{2}\right)$ in $500 \mu \mathrm{l}$ DMEM containing high glucose $(4.5 \mathrm{~g} / \mathrm{l}), 10 \% \mathrm{FBS}$, and either $1 \mu \mathrm{M}$ PD173074 or vehicle only $(0.005 \%$ DMSO $)(n=6$ replicate studies, 10-14 blastocysts/treatment/replicate). Cultures were incubated at $38.5{ }^{\circ} \mathrm{C}$ in a $20 \%$ oxygen environment. After 3 days exposure to treatment (i.e. day 11 post-IVF), medium was removed and replaced with DMEM containing 10\% fetal bovine serum (FBS) but lacking treatments. Cultures were removed from the incubator daily from days 9 to 15 post-IVF to examine the onset of outgrowth formation as described previously (Yang et al. 2011a). At day 15 post-IVF, the surface area of a subset of the outgrowths was determined by tracing the outline of the outgrowths using a Nikon SMZ1500 stereomicroscope and Nikon DXM-1200F digital camera and quantifying surface area using NIS-Elements Software (Nikon, Melville, NY, USA).

\section{Statistical analyses}

Data were analyzed by ANOVA using the general linear model of the Statistical Analysis System (SAS Institute, Inc., Cary, NC, USA). Differences between individual means were compared using pairwise comparisons (Probability of Difference (PDIFF) Analysis in SAS). Relative abundances of selected transcripts were analyzed over time and across treatments after logtransformation. Percentage data were arcsine transformed. Data are presented as arithmetic mean \pm S.E.M.

\section{Declaration of interest}

The authors declare that there is no conflict of interest that could be perceived as prejudicing the impartiality of the research reported.

\section{Funding}

This research was supported by the National Research Initiative Competitive Grant no. 2008-35203-19106 from the U.S. Department of Agriculture's National Institute of Food and Agriculture. The Opportunity Fund from the Japanese Society for Promotion of Science Fellowship supported M Ozawa during this research. 


\section{Acknowledgements}

The authors thank Dr Peter J Hansen and his laboratory for their cooperation in producing bovine embryos used in this work. The authors also thank William Rembert for his assistance with collecting ovaries and the personnel at Central Beef Packing Company for their generosity with supplying ovaries for this research.

\section{References}

Anteby EY, Natanson-Yaron S, Hamani Y, Sciaki Y, Goldman-Wohl D, Greenfield C, Ariel I \& Yagel S 2005 Fibroblast growth factor-10 and fibroblast growth factor receptors 1-4: expression and peptide localization in human decidua and placenta. European Journal of Obstetrics, Gynecology, and Reproductive Biology 119 27-35. (doi:10. 1016/j.ejogrb.2004.05.014)

Arman E, Haffner-Krausz R, Chen Y, Heath JK \& Lonai P 1998 Targeted disruption of fibroblast growth factor (FGF) receptor 2 suggests a role for FGF signaling in pregastrulation mammalian development. PNAS 95 5082-5087. (doi:10.1073/pnas.95.9.5082)

Azuma K, Tsurutani J, Sakai K, Kaneda H, Fujisaka Y, Takeda M, Watatani M, Arao T, Satoh T, Okamoto I et al. 2011 Switching addictions between HER2 and FGFR2 in HER2-positive breast tumor cells: FGFR2 as a potential target for salvage after lapatinib failure. Biochemical and Biophysical Research Communications 407 219-224. (doi:10.1016/j.bbrc.2011.03.002)

Bottcher RT \& Niehrs C 2005 Fibroblast growth factor signaling during early vertebrate development. Endocrine Reviews 26 63-77. (doi:10.1210/ er.2003-0040)

Chen C, Spencer TE \& Bazer FW 2000 Fibroblast growth factor-10: a stromal mediator of epithelial function in the ovine uterus. Biology of Reproduction 63 959-966. (doi:10.1095/biolreprod63.3.959)

Cockburn K \& Rossant J 2010 Making the blastocyst: lessons from the mouse. Journal of Clinical Investigation 120 995-1003. (doi:10.1172/ JCl41229)

Cooke FN, Pennington KA, Yang Q \& Ealy AD 2009 Several fibroblast growth factors are expressed during pre-attachment bovine conceptus development and regulate interferon- $\tau$ expression from trophectoderm. Reproduction 137 259-269. (doi:10.1530/REP-08-0396)

Daniels R, Hall V \& Trounson AO 2000 Analysis of gene transcription in bovine nuclear transfer embryos reconstructed with granulosa cell nuclei. Biology of Reproduction 63 1034-1040. (doi:10.1095/biolreprod63.4.1034)

Deng CX, Wynshaw-Boris A, Shen MM, Daugherty C, Ornitz DM \& Leder P 1994 Murine FGFR-1 is required for early postimplantation growth and axial organization. Genes and Development 8 3045-3057. (doi:10.1101/gad.8.24.3045)

Deng C, Bedford M, Li C, Xu X, Yang X, Dunmore J \& Leder P 1997 Fibroblast growth factor receptor-1 (FGFR-1) is essential for normal neural tube and limb development. Developmental Biology 185 42-54. (doi:10.1006/dbio.1997.8553)

Dunlap KA, Palmarini M, Varela M, Burghardt RC, Hayashi K, Farmer JL \& Spencer TE 2006 Endogenous retroviruses regulate periimplantation placental growth and differentiation. PNAS 103 14390-14395. (doi:10.1073/pnas.0603836103)

Ealy AD \& Yang QE 2009 Control of interferon- $\tau$ expression during early pregnancy in ruminants. American Journal of Reproductive Immunology 61 95-106. (doi:10.1111/j.1600-0897.2008.00673.x)

Ealy AD, Larson SF, Liu L, Alexenko AP, Winkelman GL, Kubisch HM, Bixby JA \& Roberts RM 2001 Polymorphic forms of expressed bovine interferon- $\tau$ genes: relative transcript abundance during early placental development, promoter sequences of genes and biological activity of protein products. Endocrinology 142 2906-2915. (doi:10.1210/en.142. 7.2906)

Elsik CG, Tellam RL, Worley KC, Gibbs RA, Muzny DM, Weinstock GM, Adelson DL, Eichler EE, Elnitski L, Guigo R et al. 2009 The genome sequence of taurine cattle: a window to ruminant biology and evolution. Science 324 522-528. (doi:10.1126/science.1169588)
Feldman B, Poueymirou W, Papaioannou VE, DeChiara TM \& Goldfarb M 1995 Requirement of FGF-4 for postimplantation mouse development. Science 267 246-249. (doi:10.1126/science.7809630)

Fields SD, Hansen PJ \& Ealy AD 2011 Fibroblast growth factor requirements for in vitro development of bovine embryos. Theriogenology 75 1466-1475. (doi:10.1016/j.theriogenology.2010.12.007)

Gilchrist RB, Lane M \& Thompson JG 2008 Oocyte-secreted factors: regulators of cumulus cell function and oocyte quality. Human Reproduction Update 14 159-177. (doi:10.1093/humupd/dmm040)

Grigor'eva EV, Shevchenko AI, Mazurok NA, Elisaphenko EA, Zhelezova Al, Shilov AG, Dyban PA, Dyban AP, Noniashvili EM, Slobodyanyuk SY et al. 2009 FGF4 independent derivation of trophoblast stem cells from the common vole. PLoS ONE 4 e7161. (doi:10.1371/ journal.pone.0007161)

Haffner-Krausz R, Gorivodsky M, Chen Y \& Lonai P 1999 Expression of Fgfr2 in the early mouse embryo indicates its involvement in preimplantation development. Mechanisms of Development 85 167-172. (doi:10.1016/S0925-4773(99)00082-9)

Itoh N \& Ornitz DM 2004 Evolution of the Fgf and Fgfr gene families. Trends in Genetics 20 563-569. (doi:10.1016/j.tig.2004.08.007)

Iyer G \& Milowsky MI 2012 Fibroblast growth factor receptor-3 in urothelial tumorigenesis. Urologic Oncology [in press].

Johnson DE, Lu J, Chen H, Werner S \& Williams LT 1991 The human fibroblast growth factor receptor genes: a common structural arrangement underlies the mechanisms for generating receptor forms that differ in their third immunoglobulin domain. Molecular and Cellular Biology 11 4627-4634.

Ka H, Jaeger LA, Johnson GA, Spencer TE \& Bazer FW 2001 Keratinocyte growth factor is up-regulated by estrogen in the porcine uterine endometrium and functions in trophectoderm cell proliferation and differentiation. Endocrinology 142 2303-2310. (doi:10.1210/en.142.6.2303)

Ka H, Al-Ramadan S, Erikson DW, Johnson GA, Burghardt RC, Spencer TE, Jaeger LA \& Bazer FW 2007 Regulation of expression of fibroblast growth factor 7 in the pig uterus by progesterone and estradiol. Biology of Reproduction 77 172-180. (doi:10.1095/biolreprod.106.056309)

Kubisch HM, Larson MA \& Roberts RM 1998 Relationship between age of blastocyst formation and interferon- $\tau$ secretion by in vitro-derived bovine embryos. Molecular Reproduction and Development 49 254-260. (doi:10. 1002/(SICl)1098-2795(199803)49:3 <254::AID-MRD5 > 3.0.CO;2-N)

Kuijk EW, Du Puy L, Van Tol HT, Oei CH, Haagsman HP, Colenbrander B \& Roelen BA 2008 Differences in early lineage segregation between mammals. Developmental Dynamics 237 918-927. (doi:10.1002/dvdy. 21480)

Kuijk EW, van Tol LT, Van de Velde H, Wubbolts R, Welling M, Geijsen N \& Roelen BA 2012 The roles of FGF and MAP kinase signaling in the segregation of the epiblast and hypoblast cell lineages in bovine and human embryos. Development 139 871-882. (doi:10.1242/dev.071688)

La Bonnardiere C, Flechon JE, Battegay S, Flechon B, Degrouard J \& Lefevre F 2002 Polarized porcine trophoblastic cell lines spontaneously secrete interferon- $\gamma$. Placenta 23 716-726. (doi:10.1053/plac.2002.0848)

Laederich MB \& Horton WA 2012 FGFR3 targeting strategies for achondroplasia. Expert Reviews in Molecular Medicine 14 e11. (doi:10.1017/erm.2012.4)

Lamont FR, Tomlinson DC, Cooper PA, Shnyder SD, Chester JD \& Knowles MA 2011 Small molecule FGF receptor inhibitors block FGFRdependent urothelial carcinoma growth in vitro and in vivo. British Journal of Cancer 104 75-82. (doi:10.1038/sj.bjc.6606016)

Larson RC, Ignotz GG \& Currie WB 1992 Transforming growth factor $\beta$ and basic fibroblast growth factor synergistically promote early bovine embryo development during the fourth cell cycle. Molecular Reproduction and Development 33 432-435. (doi:10.1002/mrd.1080330409)

Loureiro B, Bonilla L, Block J, Fear JM, Bonilla AQ \& Hansen PJ 2009 Colony-stimulating factor 2 (CSF-2) improves development and posttransfer survival of bovine embryos produced in vitro. Endocrinology $\mathbf{1 5 0}$ 5046-5054. (doi:10.1210/en.2009-0481)

Marchal L, Luxardi G, Thome V \& Kodjabachian L 2009 BMP inhibition initiates neural induction via FGF signaling and Zic genes. PNAS 106 17437-17442. (doi:10.1073/pnas.0906352106)

Michael DD, Alvarez IM, Ocon OM, Powell AM, Talbot NC, Johnson SE \& Ealy AD 2006 Fibroblast growth factor-2 is expressed by the bovine uterus and stimulates interferon- $\tau$ production in bovine trophectoderm. Endocrinology 147 3571-3579. (doi:10.1210/en.2006-0234) 
Mohammadi M, Froum S, Hamby JM, Schroeder MC, Panek RL, Lu GH, Eliseenkova AV, Green D, Schlessinger J \& Hubbard SR 1998 Crystal structure of an angiogenesis inhibitor bound to the FGF receptor tyrosine kinase domain. EMBO Journal 17 5896-5904. (doi:10.1093/emboj/17. 20.5896)

Neira JA, Tainturier D, Pena MA \& Martal J 2010 Effect of the association of IGF-I, IGF-II, bFGF, TGF- $\beta 1$, GM-CSF, and LIF on the development of bovine embryos produced in vitro. Theriogenology 73 595-604. (doi:10. 1016/j.theriogenology.2009.10.015)

Ocon-Grove OM, Cooke FN, Alvarez IM, Johnson SE, Ott TL \& Ealy AD 2008 Ovine endometrial expression of fibroblast growth factor (FGF) 2 and conceptus expression of FGF receptors during early pregnancy. Domestic Animal Endocrinology 34 135-145. (doi:10.1016/j.domaniend.2006.12.002)

Ota S, Tonou-Fujimori N, Tonou-Fujimori N, Nakayama $\mathrm{Y}$, Ito $\mathrm{Y}$, Kawamura A \& Yamasu K 2010 FGF receptor gene expression and its regulation by FGF signaling during early zebrafish development. Genesis 48 707-716. (doi:10.1002/dvg.20682)

Oulion S, Bertrand S \& Escriva H 2012 Evolution of the FGF gene family. International Journal of Evolutionary Biology [in press]. (doi:10.1155/ 2012/298147)

Pfarrer C, Weise S, Berisha B, Schams D, Leiser R, Hoffmann B \& Schuler G 2006 Fibroblast growth factor (FGF)-1, FGF2, FGF7 and FGF receptors are uniformly expressed in trophoblast giant cells during restricted trophoblast invasion in cows. Placenta 27 758-770. (doi:10.1016/j. placenta.2005.06.007)

Powers CJ, McLeskey SW \& Wellstein A 2000 Fibroblast growth factors, their receptors and signaling. Endocrine-Related Cancer 7 165-197. (doi:10.1677/erc.0.0070165)

Purcell SH, Cantlon JD, Wright CD, Henkes LE, Seidel GE Jr \& Anthony RV 2009 The involvement of proline-rich 15 in early conceptus development in sheep. Biology of Reproduction 81 1112-1121. (doi:10.1095/ biolreprod.109.076190)

Rappolee DA, Patel Y \& Jacobson K 1998 Expression of fibroblast growth factor receptors in peri-implantation mouse embryos. Molecular Reproduction and Development 51 254-264. (doi:10.1002/(SICl)10982795(199811)51:3 <254::AID-MRD4 > 3.0.CO;2-O)

Robert C, McGraw S, Massicotte L, Pravetoni M, Gandolfi F \& Sirard MA 2002 Quantification of housekeeping transcript levels during the development of bovine preimplantation embryos. Biology of Reproduction 67 1465-1472. (doi:10.1095/biolreprod.102.006320)

Robinson RS, Fray MD, Wathes DC, Lamming GE \& Mann GE 2006 In vivo expression of interferon $\tau$ mRNA by the embryonic trophoblast and uterine concentrations of interferon $\tau$ protein during early pregnancy in the cow. Molecular Reproduction and Development 73 470-474. (doi:10.1002/mrd.20431)

Satterfield MC, Hayashi K, Song G, Black SG, Bazer FW \& Spencer TE 2008 Progesterone regulates FGF10, MET, IGFBP1, and IGFBP3 in the endometrium of the ovine uterus. Biology of Reproduction $\mathbf{7 9}$ 1226-1236. (doi:10.1095/biolreprod.108.071787)

Shimada A, Nakano H, Takahashi T, Imai K \& Hashizume K 2001 Isolation and characterization of a bovine blastocyst-derived trophoblastic cell line, BT-1: development of a culture system in the absence of feeder cell. Placenta 22 652-662. (doi:10.1053/plac.2001.0702)

Skaper SD, Kee WJ, Facci L, Macdonald G, Doherty P \& Walsh FS 2000 The FGFR1 inhibitor PD 173074 selectively and potently antagonizes FGF-2 neurotrophic and neurotropic effects. Journal of Neurochemistry 75 1520-1527. (doi:10.1046/j.1471-4159.2000.0751520.x)
Talbot NC, Caperna TJ, Edwards JL, Garrett W, Wells KD \& Ealy AD 2000 Bovine blastocyst-derived trophectoderm and endoderm cell cultures: interferon $\tau$ and transferrin expression as respective in vitro markers. Biology of Reproduction 62 235-247. (doi:10.1095/biolreprod62.2.235)

Talbot NC, Powell AM, Camp M \& Ealy AD 2007 Establishment of a bovine blastocyst-derived cell line collection for the comparative analysis of embryos created in vivo and by in vitro fertilization, somatic cell nuclear transfer, or parthenogenetic activation. In Vitro Cellular \& Developmental Biology 43 59-71. (doi:10.1007/s11626-007-9013-9)

Tanaka S, Kunath T, Hadjantonakis AK, Nagy A \& Rossant J 1998 Promotion of trophoblast stem cell proliferation by FGF4. Science 282 2072-2075. (doi:10.1126/science.282.5396.2072)

Telford NA, Watson AJ \& Schultz GA 1990 Transition from maternal to embryonic control in early mammalian development: a comparison of several species. Molecular Reproduction and Development 26 90-100. (doi:10.1002/mrd.1080260113)

Tenhagen M, van Diest PJ, Ivanova IA, van der Wall E \& van der Groep P 2012 Fibroblast growth factor receptors in breast cancer: expression, downstream effects, and possible drug targets. Endocrine-Related Cancer 19 R115-R129. (doi:10.1530/ERC-12-0060)

Vandevoort CA, Thirkill TL \& Douglas GC 2007 Blastocyst-derived trophoblast stem cells from the rhesus monkey. Stem Cells and Development 16 779-788. (doi:10.1089/scd.2007.0020)

Yamaguchi TP, Harpal K, Henkemeyer M \& Rossant J 1994 Fgfr-1 is required for embryonic growth and mesodermal patterning during mouse gastrulation. Genes and Development 8 3032-3044. (doi:10.1101/gad. 8.24.3032)

Yamanaka Y, Lanner F \& Rossant J 2010 FGF signal-dependent segregation of primitive endoderm and epiblast in the mouse blastocyst. Development 137 715-724. (doi:10.1242/dev.043471)

Yang QE, Fields SD, Zhang K, Ozawa M, Johnson SE \& Ealy AD 2011a Fibroblast growth factor 2 promotes primitive endoderm development in bovine blastocyst outgrowths. Biology of Reproduction 85 946-953. (doi:10.1095/biolreprod.111.093203)

Yang QE, Giassetti MI \& Ealy AD $2011 b$ Fibroblast growth factors activate mitogen-activated protein kinase pathways to promote migration in ovine trophoblast cells. Reproduction 141 707-714. (doi:10.1530/REP10-0541)

Zhang K \& Ealy AD 2012 Disruption of fibroblast growth factor receptor signaling in bovine cumulus-oocyte complexes during in vitro maturation reduces subsequent embryonic development. Domestic Animal Endocrinology 42 230-238. (doi:10.1016/j.domaniend.2011. 12.006)

Zhang K, Hansen PJ \& Ealy AD 2010 Fibroblast growth factor 10 enhances bovine oocyte maturation and developmental competence in vitro. Reproduction 140 815-826. (doi:10.1530/REP-10-0190)

Zimin AV, Delcher AL, Florea L, Kelley DR, Schatz MC, Puiu D, Hanrahan F, Pertea G, Van Tassell CP, Sonstegard TS et al. 2009 A whole-genome assembly of the domestic cow, Bos taurus. Genome Biology 10 R42. (doi:10.1186/gb-2009-10-4-r42)

Received 12 June 2012

First decision 23 July 2012

Revised manuscript received 5 December 2012

Accepted 10 December 2012 